\title{
The Ultimate Technology
}

by George Maney

Awhile back I was cleaning out my attic and came across what appeared to be a magic lamp. So I rubbed the thing a few times and, sure enough, out pops a genie.

I stared for a moment, then quickly recovered my composure. "Well then, I suppose you're going to grant me three wishes?" "No" the genie replied. "There's a serious shortage of wishes just now, so you only get one wish. Make a wise choice. No refunds or returns."

I knew exactly what I wanted. "I wish for the exclusive rights to the ultimate technology. I insist on the rights to single most powerful technology in any human civilization anywhere including all past, present, and future civilizations."

The genie breathed an audible sigh of relief. "Granted!" he cried. "I was deathly afraid that you were going to wish for something terribly difficult."

As the genie started back into his lamp I called out after him. "By the way, which technology did you grant me the exclusive rights to?"

The genie turned around. "Oh, I apologize. I thought that was obvious. I granted you the exclusive rights to the technology of practical language."

I thought about this for a just second. "Whoa, hold on a minute! Practical language is not a technology!"

The genie replied "Of course practical language is a technology!" 
"It is the one truly ultimate technology. It is the only technology that is always the starting point for every other technology."

"Moreover, practical language is the one absolutely indispensable technology in any human civilization. It is the only technology which, if abolished, would cause the immediate and complete collapse of any human civilization."

"Practical language is a high technology with a remarkably rich, regular, and redundant technological structure. It is the uniquely powerful and profound technology that enables all modeling of every sort of mundane and managerial artifact in any human civilization."

"Well" I said, "how is it that I now have exclusive rights to this technology?" The genie replied "That's simple".

"Nobody thinks of practical language as a technology per se any more. This view was popular and productive in the first half of the twentieth century but has been utterly unfashionable now for decades. Today everyone else has completely forgotten about the technological approach to understanding the substance of practical language. So it's all yours now. Go for it! It's the ultimate high technology trophy hack."

"J ust one more thing" I replied. "How do I enforce my exclusive rights to this ultimate technology?" The genie smiled.

"Remember that you didn't wish for the exclusive rights in perpetuity. That's a whole different sort of exceptionally difficult wish. As of this very moment you're the only person on the planet who knows that practical language is the ultimate technology. If you really want to maintain your exclusivity then all you need to do is keep your mouth shut."

With this the genie disappeared back into his lamp for good. 
George Maney is an independent investigator working in practical language automation and institutional infodynamics. See www.proseology.com $<$ http://www.proseology.com> . He developed this piece as an aid in making the point that viewing practical language as a technology per se can be a particularly useful approach in practical language automation. He says that it has worked remarkably well for this purpose with various audiences.

Ubiquity Volume 7, Issue 24 (June 27 - July 4, 2006)

<http://www.acm.org/ubiquity/> 